\title{
EXPERIMENTAL STUDY ON GROUND STRENGTHENING AND ELECTRIC POWER GENERATION WITH USING RECYCLED ASPHALT PAVEMENT MATERIAL
}

\author{
*Shoji Yokohama ${ }^{1}$ \\ ${ }^{1}$ Faculty of Engineering, Hokkaido University, Japan
}

*Corresponding Author, Received: 06 Oct. 2021, Revised: 01 Dec. 2021, Accepted: 09 Jan. 2022

\begin{abstract}
To ensure a safe living environment against frequent natural disasters, a mechanical reinforcement of the ground and a stable power supply are required. Reusing resources is essential to the development of a sustainable social life system. In this study, a comprehensive system is proposed to strengthen the ground and generate electrical energy by using recycled asphalt pavement material. In the proposed system, the new T-shaped unit is the primary tool for upgrading bearing capacity and generating electric power. The T-shaped unit is inserted into the ground and the surface of the ground is covered with recycled asphalt pavement material (RAP). The bearing capacity of the ground is improved and the deformation of the ground is restrained by the T-shaped unit and the RAP placed on the ground surface. On the other hand, Peltier elements are built into the T-shaped unit. Electric power can be generated by the thermoelectric effect by converting the temperature difference between the ground surface and the subsoil. In this study, the bearing capacity of the reinforced ground and power generation behavior are studied through laboratory tests and field monitoring, respectively. It is shown that the bearing capacity of the ground is improved by the RAP laying and insertion of the T-shaped unit by the results of laboratory tests. Electricity generation may be recognized from the results of field monitoring. Based on these experimental results, the feasibility of a comprehensive system for strengthening the ground, generating electricity, and reusing construction waste material is discussed.
\end{abstract}

Keywords: Recycled asphalt pavement material, Ground protection, Power generation, Electromagnetic force

\section{INTRODUCTION}

In recent years, the damage of natural disasters has become enormous. The damage was also prolonged due to the collapse of the ground and the interruption of the energy supply needed for daily life by injuring the various infrastructures. It is beneficial for engineering that the importance of suggesting and researching for practical use a method that achieves both ground protection and stable energy supply. Moreover, it is important to make efficient use of construction materials in the area of civil engineering to build a sustainable social system.

In this study, a concept is proposed to achieve ground protection and power generation at the same time while reusing recycled asphalt pavement material. The feasibility of the proposed system is examined within the framework of experimental studies. Concerning ground protection, a method to improve the bearing capacity of the ground by inserting a reinforcing tool with a magnetic force around the reinforcing tool is proposed in the present study. The bearing capacity of the ground inserted in the reinforcing tool was examined by the laboratory tests. In this study, a power generation unit with built-in thermoelectric elements was also prepared. The efficiency of an electricity generation

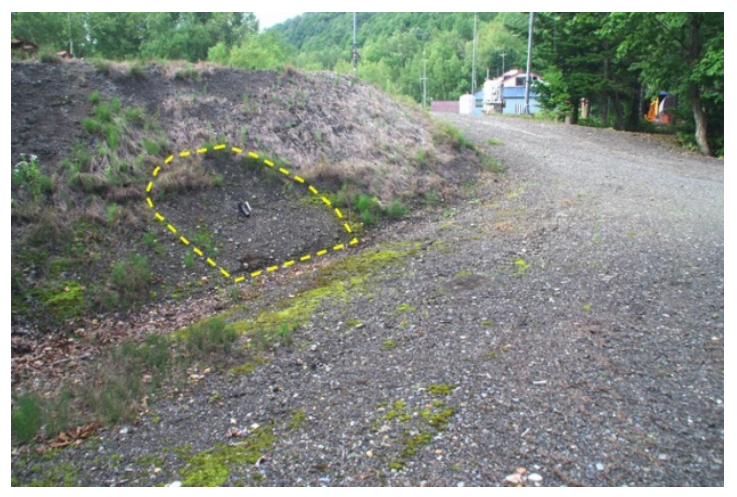

Fig.1 Ground surface protected by RAP

method of the prepared unit using ground temperature was investigated by field monitoring. Based on the results of the laboratory tests and the field monitoring, the feasibility of a system that provides both ground protection and power generation using recycled asphalt pavement materials and ground surface temperature are discussed.

\section{APPLICATION OF RECYCLED ASPHALT PAVEMENT MATERIAL FOR GROUND SURFACE PROTECTION}

Before starting this study, investigating the 


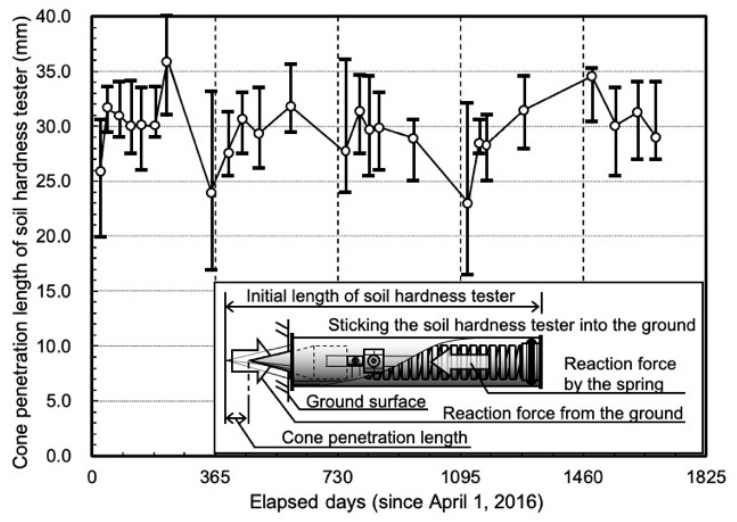

Fig.2 Soil hardness at the protected ground surface by RAP

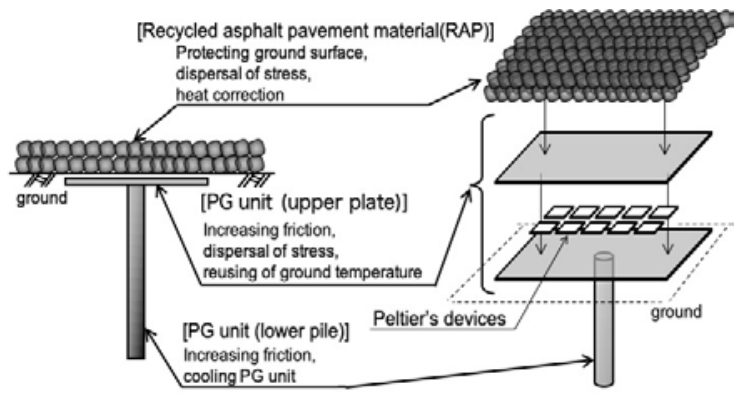

Fig.3 Concept of comprehensive system for ground protection and power generation using RAP

construction case where the recycled asphalt pavement material (hereinafter referred to as RAP) is used as a protective material for ground surface has been performed. Fig.1 shows the state of the protection of the ground surface, including the slope, using recycled asphalt pavement material, which was carried out in Uryu-cho, Hokkaido, JAPAN. The image was taken in September 2020. The whole surface was covered by RAP material. It can be seen the ground surface was kept on stable from this figure. This ground protection work was completed in June 2009 to prevent the presence of mud on the ground surface and to facilitate the passage of vehicles for construction work. The compaction control at the RAP layer was not planned.

Fig.2 shows the value of soil hardness on the slope surface (see the area dotted line in Fig.1) covered with RAP. Soil hardness has been measured with a soil hardness tester. When the soil hardness tester was stuck to the ground surface, the cone moved into the tester and the length of penetration of the cone could be read by the scale. The high value of the cone penetration length can be read if the ground surface is hard. The hardness of the ground was measured at 10 points within the dotted line in Fig.1. The maximum, minimum, and average values of soil hardness are plotted in Fig. 2. From this figure, it can be seen the soil hardness value was approximately $30 \mathrm{~mm}$ from 2016 to 2020 . It was also found that soil hardness in the spring was slightly lower than in other seasons. This result suggests that the long-term protection of the ground surface is possible by using recycled asphalt pavement material.

\section{CONCEPT OF SYSTEM FOR GROUND PROTECTION, POWER GENERATION, AND REUSING RECYCLED ASPHALT PAVE-MENT MATERIAL}

Fig.3 illustrates the concept of a comprehensive system for ground protection - power generation construction waste material reusing. In the proposed system, the ground surface is covered with RAP, and a T-shaped unit (PG unit) is inserted into the ground to reinforce and protect the ground. RAP has several mechanical advantages [1]. The advantages are as follows;

1. The cyclic strength of sandy soil mixed with RAP is greater than that of plain sandy soil.

2. The bonding occurs between soil particles when the RAP specimen is compressed to a low confining pressure during the triaxial compression test.

The mechanical characteristic of RAP was investigated and suggested its use for the construction material by many studies (ex. [2, 3]).

RAP is adopted as the testing material in this study because these advantages are effective in achieving the proposed system [4]. In this study, the tool used for the proposed system that carries out ground strengthening and power generation is referred to as the PG unit. The PG unit has a form in which the slab and the pile are linked. It is thought that ground reinforcement is accomplished by inserting the PG unit into the ground and causing friction between the PG unit and the ground. On the other hand, the PG unit, which is a built-in Peltier element [5] attempts to generate electric power using the temperature difference between the ground surface and the subsoil. Such a power production is carried out due to the Seebeck effect seen at which the temperature difference occurred on the Peltier's devices [6, 7, 8]. The RAP covering the ground surface is exposed to solar radiation and plays a role in increasing the temperature difference on the surface of the PG unit.

\section{MECHANICAL PROPERTIES OF THE PROTECTED GROUND}

The behavior of the ground protected by the PG unit and recycled asphalt waste material (RAP) was investigated by a laboratory test. Fig. 4 illustrates the test apparatus. The test apparatus consists mainly of a cylindrical acrylic cell with an internal diameter of $200 \mathrm{~mm}$, a loading plate, and a loading frame. Toyoura sand ( $\mathrm{T}$ sand) was used as the testing material. The ground was prepared with a 


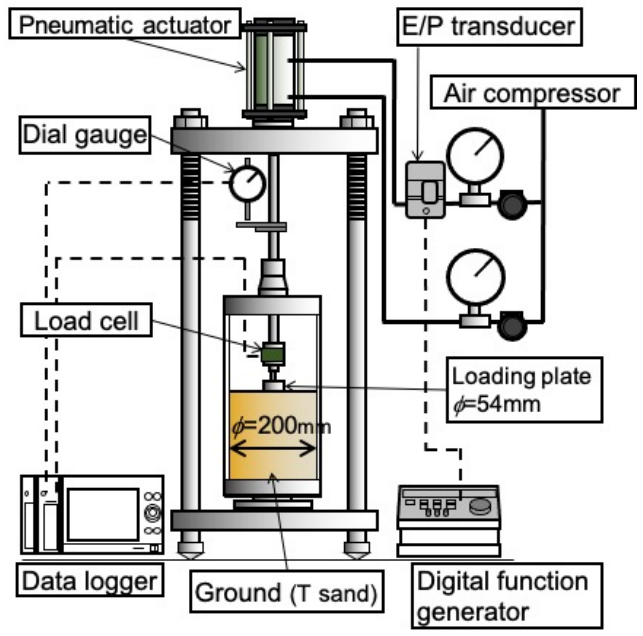

Fig.4 Test apparatus for bearing capacity of the protected ground

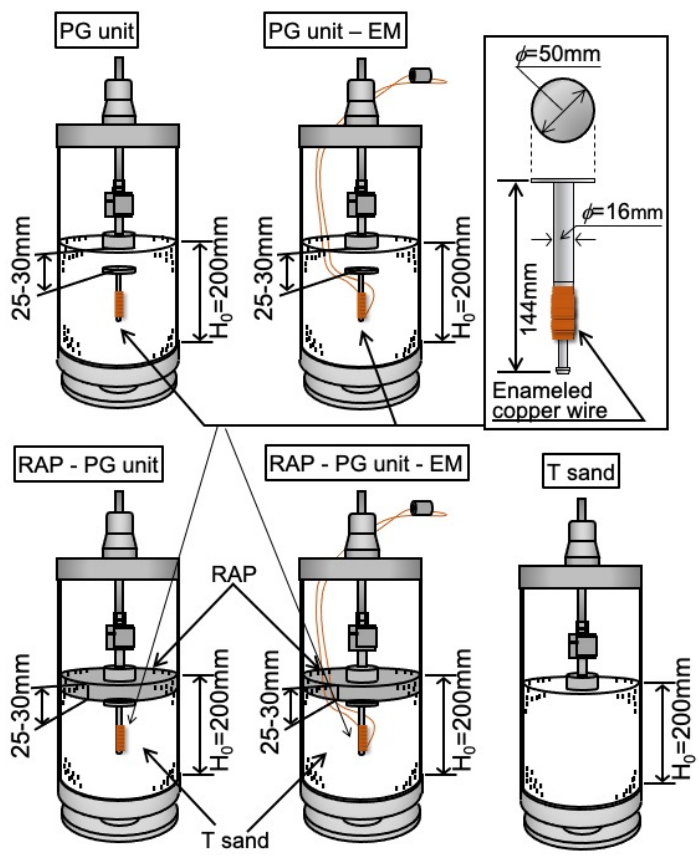

Fig.5 Conditions for laboratory testing

height of approximately $200 \mathrm{~mm}$ by the multiple sieves pluviation method (MSP method [9]). A loading plate with a diameter of $54 \mathrm{~mm}$ was placed at the center of the ground surface, and a vertical force was applied. The vertical load was increased to approximately $23 \mathrm{~N}$ in 10 minutes. The vertical force and the displacement of the loading plate were measured using a load cell and dial gauge connected to the test equipment.

Fig. 5 shows the test conditions adopted in the study. In this study, the T-shaped reinforcing tool (referred to as the PG unit) made of iron was inserted into the ground. Enameled wire with a length of $30 \mathrm{~m}$ and a diameter of $0.4 \mathrm{~mm}$ was wound into a coil around the lower pile of the PG unit. In the PG unit case, the PG unit was inserted into the testing ground. At PG unit-EM case, the electric

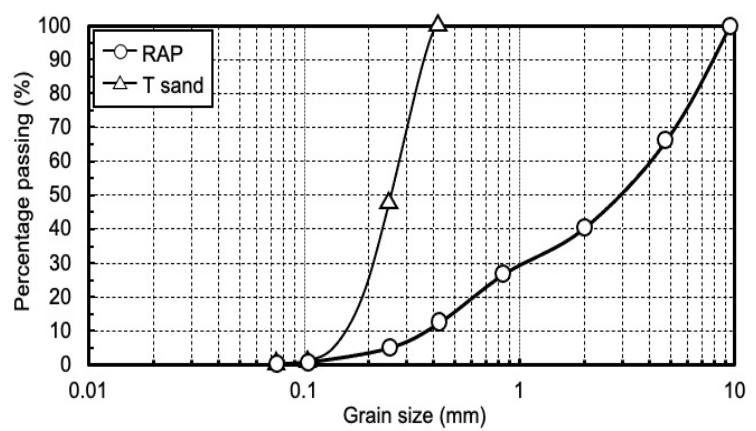

Fig.6 Grain size distributions of RAP and T sand
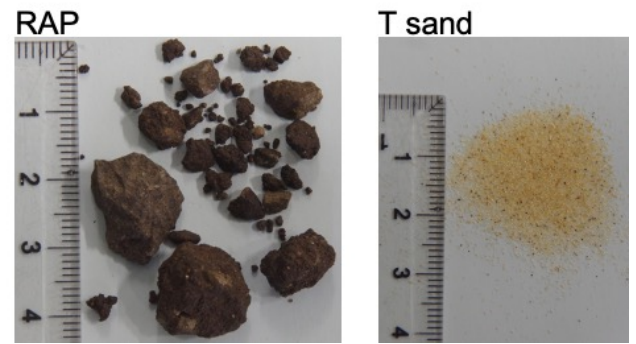

Fig.7 Appearance of RAP and T sand

Table 1 The index of phvsical properties of samples

\begin{tabular}{lcccc}
\hline & & $\begin{array}{c}\rho_{\mathrm{s}} \\
\left(\mathrm{g} / \mathrm{cm}^{3}\right)\end{array}$ & $\begin{array}{c}\rho_{\mathrm{dmax}} \\
\left(\mathrm{g} / \mathrm{cm}^{3}\right)\end{array}$ & $\begin{array}{c}\rho_{\text {dmin }} \\
\left(\mathrm{g} / \mathrm{cm}^{3}\right)\end{array}$ \\
\hline $\begin{array}{l}\text { Recycled asphalt } \\
\text { pavement material }\end{array}$ & (RAP) & 2.366 & 1.607 & 1.412 \\
\hline Toyoura sand & (T sand) & 2.649 & 1.636 & 1.344 \\
\hline
\end{tabular}

current was passed through the enameled wire of the inserted PG unit. The conditions that the ground above the PG unit was replaced with recycled asphalt pavement material (RAP) are referred to as RAP-PG unit case and RAP-PG unit-EM case. The behavior of the ground was observed without any strengthening in the $\mathrm{T}$ sand case. The electric current at the PG unit comes from a power source in which six nickel-metal hydride batteries (6500 $\mathrm{mAh}, 1.2 \mathrm{~V}$ ) were connected in series. The purpose of the electric current supply to the PG unit is to generate a magnetic force from the PG unit. The magnetic force can attract the iron sand in $\mathrm{T}$ sand towards the PG unit to enhance the friction with the ground. Fig.6 and Fig.7 show the particle size distribution and appearance of the samples (RAP and $T$ sand) used in the study. From these figures, it can be seen that $\mathrm{T}$ sand is fine sand with uniform particle size, while RAP has a black surface and a uniformity coefficient of 10 or more. The RAP was a sample collected from a plant in Sapporo City in August 2014, and the maximum particle size was adjusted to $9.5 \mathrm{~mm}$ for this study. The index of the physical properties of each sample is shown in Table 1. It was confirmed in advance that the iron sand content of the $\mathrm{T}$ sand used in this study is approximately $0.43 \%$ of the total $\mathrm{T}$ sand mass. 


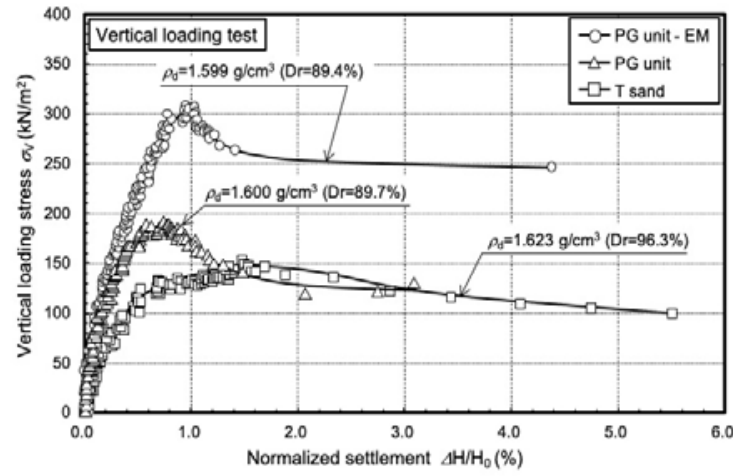

Fig.8 Bearing capacity for $\mathrm{T}$ sand ground protected by PG unit

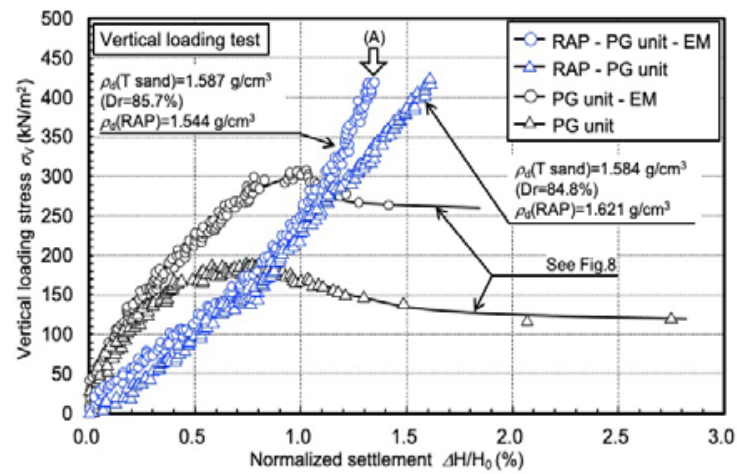

Fig.9 Bearing capacity for T sand ground protected by PG unit and RAP

Fig. 8 shows the relationship between the loading stress $\sigma_{\mathrm{v}}$ and the normalized settlement of the loading plate $\Delta H / H_{0}$ in the case of PG unit, PG unit-EM, and $\mathrm{T}$ sand case. Where, $\Delta H$ and $H_{0}$ are the settlement of the loading plate and the initial ground thickness, respectively. The relative density Dr of the ground is around $90 \%$. It can be found that the maximum load stress in the PG unit and PG unit-EM cases are higher than that in the $\mathrm{T}$ sand case. The maximum loading stress for the PG unitEM case is the highest of them all. From the result, it can be inferred that the magnetic force generated around the PG unit helped to improve the bearing capacity.

Next, the residual state after the appearance of the maximum value of the loading stress is focused. It is shown that the loading stress in the residual state in the PG unit-EM case reaches about two times the value in the T sand and PG unit cases. This fact indicates that the magnetic force around the PG unit affected the distribution of stresses in the ground as a result of the effect of attracting iron sand and the value of the loading stress in the residual state has become higher than in the case without magnetic force. From these results, it was indicated that the friction between the sand ground and the PG unit had been increased by the magnetic force, and the bearing capacity had been improved.

The behavior of the sand ground protected by the RAP layer is examined. Fig. 9 shows the relationship between the loading stress $\sigma_{\mathrm{v}}$ and the normalized settlement $\Delta H / H_{0}$ obtained in the case of the RAP-PG unit and RAP-PG unit-EM. In both cases, the relative density of the T sand ground $D_{\mathrm{r}}$ is about $85 \%$. For comparative purposes, the results of the cases of PG unit and PG unit-EM (see Fig. 8) are also presented in Fig.9. The figure shows that the increase in loading stress at the case of RAP-PG unit and RAP-PG unit-EM when the normalized settlement $\Delta H / H_{0}$ is small is slower than in the test cases without the RAP layer (PG unit and PG unitEM case). When $\Delta H / H_{0}$ becomes about $1.1 \%$ or greater, a higher loading stress value is displayed compared with PG unit and PG unit-EM cases. Although the peak value of the loading stress could not be measured because of the measuring capacity of the load cell mounted on the test apparatus, in the cases of the RAP-PG unit and RAP-PG unit-EM, a tendency to increase the bearing capacity of the ground by using RAP layer is described. The increase in bearing capacity is also considered to be due to the remarkable compressibility of the RAP and the bonding behavior due to contact between the RAP particles [10].

\section{POWER GENERATION BY USING RAP AND GROUND TEMPERATURE}

Fig.10 shows the configuration of the power generation equipment (referred to as the PG unit for power generation) used in the field monitoring of power generation behavior in this study. The PG unit for power generation is mainly composed of an upper plate made of a sandwich of a Peltier's devices between aluminum plates with the thickness, width, and length in $0.3 \mathrm{~mm}, 300 \mathrm{~mm}$, and $200 \mathrm{~mm}$. A group of components for cooling the back face of the upper plate are also attached. In the upper plate of the PG unit for power generation, 30 Peltier elements are connected in series and arranged side by side. The Peltier's device is a square with a side of $40 \mathrm{~mm}$ and a thickness of 4 $\mathrm{mm}$, its maximum heat absorption is $51 \mathrm{~W}$, and the maximum voltage that can be input to the Peltier's device from the outside is $15.4 \mathrm{~V}$. Thermometers were also attached to the front and back face of the upper plate of the $\mathrm{PG}$ unit to provide the temperature information.

On the surface of the upper plate of the PG unit, a heat collector box consisting of a heat-insulating material and an aluminum plate was attached. The recycled asphalt pavement material (RAP) was applied inside the heat collector box to increase the surface temperature. A cooling agent (a commercially available product containing a highly 


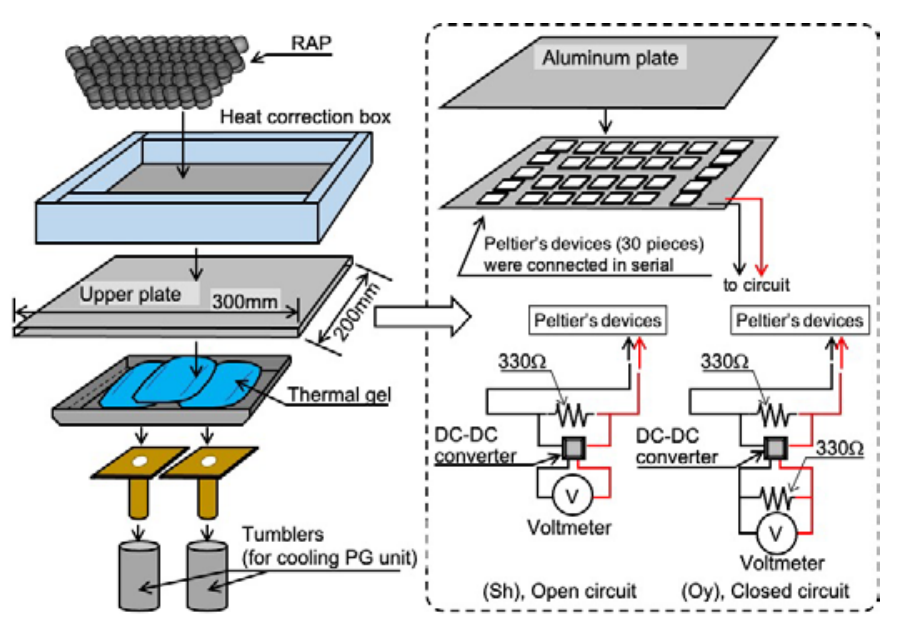

Fig.10 Configuration of the PG unit for power generation
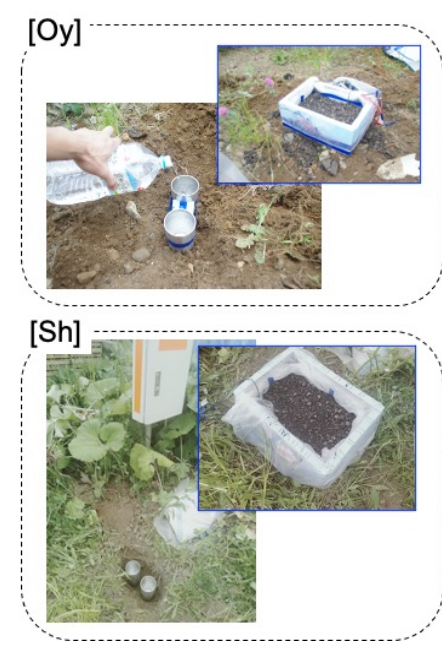

Fig.11 Situation of field monitoring at [Oy] and [Sh]
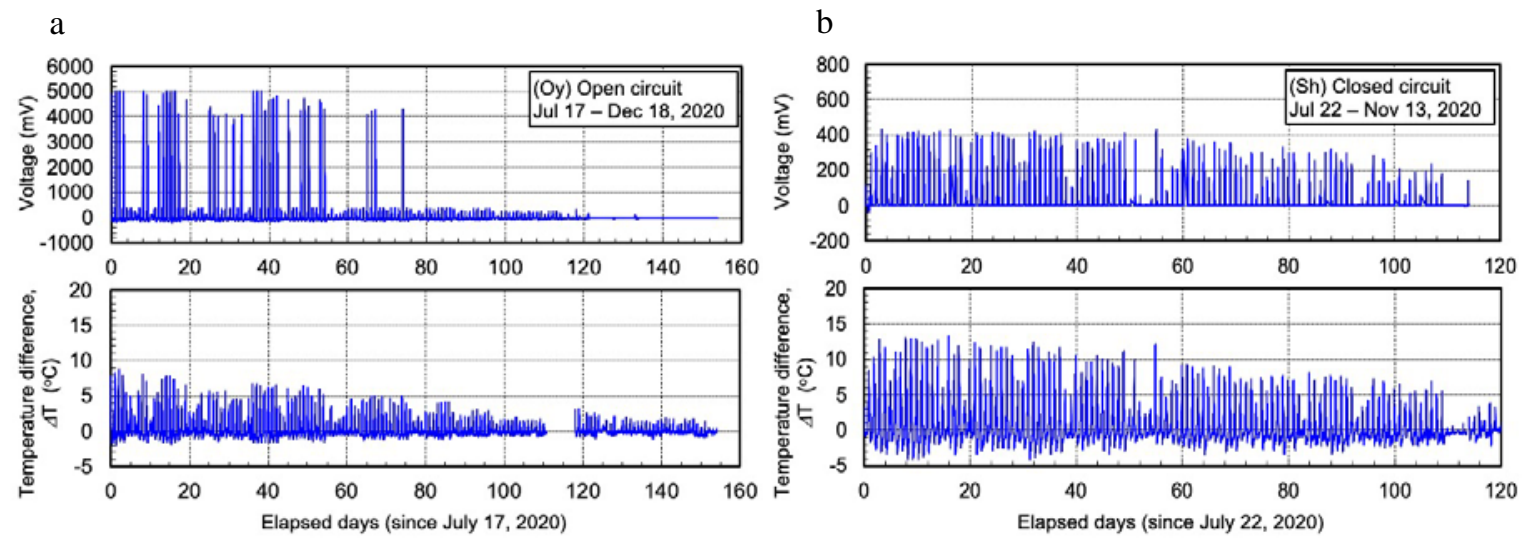

Fig.12 Voltage and temperature difference of PG unit, (a) : [Oy](Open circuit), (b) : [Sh](Closed circuit)

water-absorbent resin, etc.) was attached to the back face of the upper plate, and two brass fixing bases were attached to cool the PG unit for power generation. When adjusting the PG unit to the outdoors, two stainless steel tumblers filled with tap water were prepared. The stainless-steel tumblers were buried in the ground so that the protrusions of the fixed base attached to the PG unit could be inserted. In this study, two types of electric circuits were prepared. In each circuit, a $330 \Omega$ resistor and a step-up DC-DC converter (maximum output 5V) were connected to the wiring from the Peltier's device. One of them is to connect a voltmeter with the circuit from the step-up DC-DC converter as an open type (referred to as open circuit) to confirm whether the step-up DC-DC converter can operate. On the other hand, a $330 \Omega$ resistor and a voltmeter were connected to the output circuit of the step-up DC-DC converter (called a closed circuit). In a closed circuit, the electrical energy produced at the resistance has been examined.

Field monitoring was carried out at two locations of Oyachi (denoted as [Oy]) and Shinoro (denoted as [Sh]) in Sapporo city, JAPAN. In [Oy],
PG units with open circuit was used. In [Sh], the PG unit with a closed-circuit was used. Fig. 11 shows the set-up situation of the PG unit in [Oy] and [Sh]. A tumbler filled with tap water is buried near the ground surface, the PG unit is put on it. The recycled asphalt pavement material is spread with a thickness of about $50 \mathrm{~mm}$ inside the heat collection box.

Fig.12 (a) and (b) show the measured voltage and temperature difference of PG unit $\Delta T$ at [Oy] and [Sh]. The temperature difference $\Delta T$ is defined as the difference between the temperature on the front surface and the temperature on the backside of the upper plate of the PG unit. According to Fig.12 (a), it was found that the output voltage corresponded to the fluctuation of the temperature difference $\Delta T$ and that the voltage sometimes may reach $5000 \mathrm{mV}$. Such voltage behavior indicates that the step-up DC-DC converter can be performed by the output electrical power from the PG unit when the temperature difference can be secured. From Fig.12 (b), it was found that the temperature difference $\Delta T$ and the voltage at the resistance of $330 \Omega$ were observed to be $13{ }^{\circ} \mathrm{C}$ and $400 \mathrm{mV}$, 

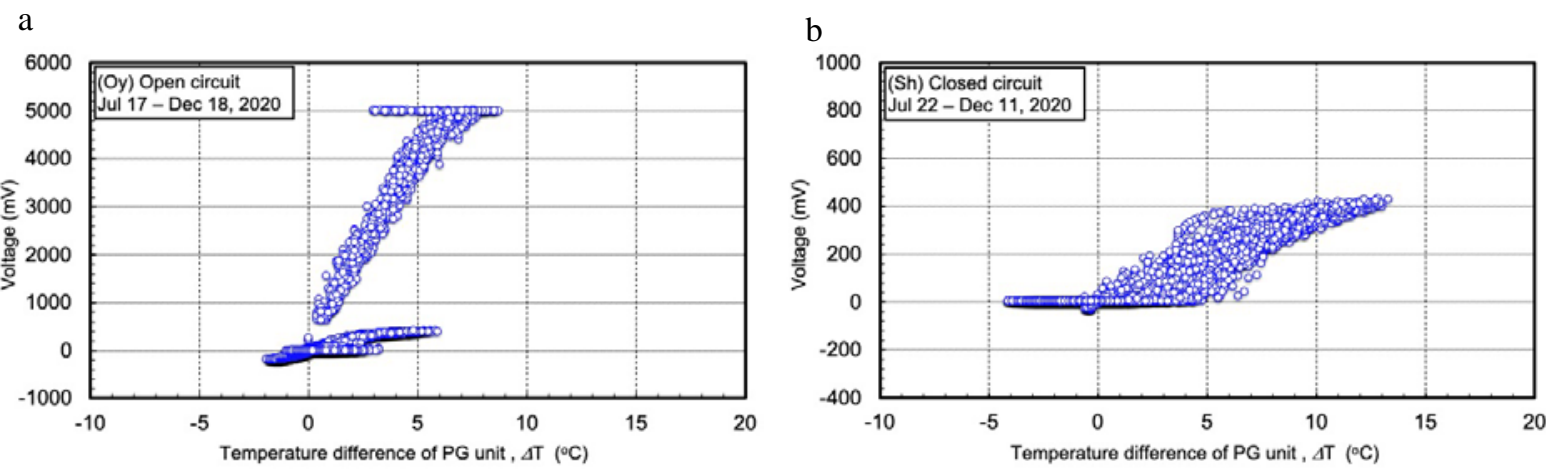

Fig.13 Relationship between voltage and temperature difference (a) : [Oy](Open circuit), (b) : [Sh](Closed circuit)

respectively. Although the behavior of the output voltage depends on the season and the day temperature, it is possible to set the temperature difference of the PG unit at $10{ }^{\circ} \mathrm{C}$, furthermore, it can be also observed that electrical power can be produced.

The relations between the output voltage and the temperature difference $\Delta T$ are given in Fig.13 (a) and (b). According to the results of [Oy] (see Fig.13 (a)), when the temperature difference $\Delta T$ was $3{ }^{\circ} \mathrm{C}$ or higher, the step-up DC-DC converter was activated and the output voltage of about $5 \mathrm{~V}$ was observed. On the other hand, there were cases where the output voltage was 400 to $500 \mathrm{mV}$ even when the temperature difference $\Delta T$ was $5{ }^{\circ} \mathrm{C}$ or higher on Fig. 13 (b). From these results, it is recognized that the electrical power required for the operation of the step-up DC-DC converter can be produced if the temperature difference $\Delta T$ could be larger than a certain value. It is also noted that the other factor from the temperature difference $\Delta T$ must be taken into account for the stable operation of the step-up DC-DC converter.

\section{CONCLUSIONS}

In this study, the comprehensive concept for implementing ground reinforcement and power generation with recycled asphalt pavement materials was suggested. To confirm the implementation of the concept, laboratory tests on ground strengthening and field monitoring of electrical power production were carried out. The main findings of the study are as follows;

1. When recycled asphalt pavement material is laid on the ground surface and a reinforcement tool is inserted into the ground, the bearing capacity of the ground can be improved. It was also shown that the bearing capacity can be further improved by generating a magnetic force around the reinforcing tool inserted into the ground.

2. The electrical power output can be seen using the power generation unit with integrated thermoelectric devices. The power generation unit was installed near the surface of the ground and covered with recycled asphalt pavement material. Stable power generation is necessary to keep the large temperature difference between the front and back faces of the power generation unit.

From the above results, if a sturdy reinforcing tool that is integrated with a thermoelectric element can be manufactured, it may be possible to embody the system for ground protection and power generation using recycled asphalt pavement material.

\section{ACKNOWLEDGMENTS}

The author received the generous support of the field monitoring for the ground protection and the electric power generation from Mr. Juichi Hatakeyama in Uryu-cho, Hokkaido, Japan. This study was supported by JSPS KAKENHI Grant Number JP18K04341.

\section{REFERENCES}

[1] Yokohama S. and Sato A., Cyclic mechanical properties of sandy soil by mixing recycled asphalt pavement material, International Journal of GEOMATE, Vol.16, Issue 58, 2019, pp.41-47.

[2] Soleimanbeigi, A. Tuncer B. Edil, and Craig H. B. Creep response of recycled asphalt shingles, Canadian Geotechnical Journal, Vol.51, 2014, pp.103-114.

[3] Soleimanbeigi, A., Edil T. B., and Benson C. H., Engineering Properties of recycled materials for use as embankment fill, Proceedings of Geo-Congress 2014 Technical Papers, 2014, pp.3654-3657.

[4] Yokohama S., Feasibility of total system for ground protection - power generation construction waste material reusing, Japanese 
Geotechnical Society Special Publication, Third International Symposium on Coupled Phenomena in Environmental Geotechnics, Vol. 9, Issue 9, 2021, pp.418-423.

[5] Ahiska R., Mamur H., A review: Thermoelectric generators in renewable energy, International Journal of Renewable Energy Research, Vol.4, No.1, 2014, pp.128-136.

[6] ROWE D. M., Thermoelectric, and environmentally-friendly source of electrical power, Renewable Energy, Vol. 16, 1999, pp.1251-1256.

[7] LeBlanc S., Thermoelectric generators: Linking material properties and systems engineering for waste heat recovery applications, Sustainable Materials, and Technologies, Vol. 1-2, 2014, pp.26-35.
[8] Liu W., Jie Q., Kim H. S., and Ren Z., Current progress and future challenges in thermoelectric power generation: From materials to devices, Acta Materialia, Vol. 87, 2015, pp.357-376.

[9] Miura S. and Toki S., A sample preparation method and its effect on static and cyclic deformation-strength properties of sand, Soils, and Foundations, Vol. 22, No.1, 1982, pp.6177.

[10]Lee, K.L., Adhesion bonds in sands at high pressure, Journal of the Geotechnical Engineering Division, Proceedings of the ASCE, 103, GT8, 1977, pp.908-913.

Copyright (C) Int. J. of GEOMATE All rights reserved, including making copies unless permission is obtained from the copyright proprietors. 